\title{
ISSUe OF High Precision MANUfaCtURing ANALYSIS IN AUTOMOTIVE INDUSTRY
}

\author{
Katerina Bicova, Jan Kutlwaser \& Josef Sklenicka
}
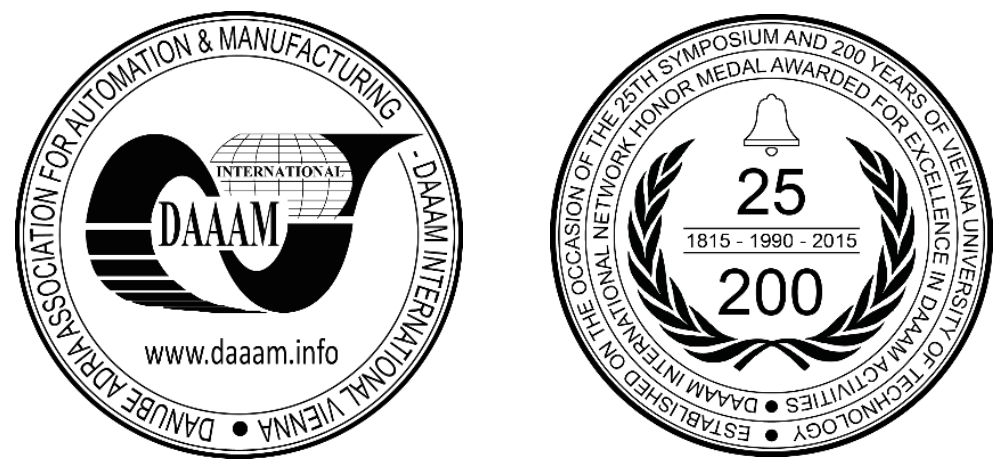

This Publication has to be referred as: Bicova, K[aterina]; Kutlwaser, J[an] \& Sklenicka, J[osef] (2016). Issue of High Precision Manufacturing Analysis in Automotive Industry, Proceedings of the 27th DAAAM International Symposium, pp.0353-0357, B. Katalinic (Ed.), Published by DAAAM International, ISBN 978-3-902734-08-2, ISSN 1726-9679, Vienna, Austria

DOI: $10.2507 / 27$ th.daaam.proceedings.052

\begin{abstract}
The contribution deals with issue of evaluation of precise production of machine parts. It works with detailed analysis of data from serial production from automotive industry, where the precise production plays the main role. Authors used a Pareto analysis for evaluation of data, which was collected during production of one batch of parts and analyzed those data. The batch is re-measured in laboratory conditions, new analysis is conducted and several suggestions for production process improvement are given.
\end{abstract}

Keywords: Automotive industry; precise manufacturing; evaluation; Pareto analysis; roundness.

\section{Introduction}

Automotive industry belongs to the most competitive branch of mechanical engineering. Companies fight for reach and prove their good names. Progressive technologies, product properties and services for customers are constantly developing.

This contribution describes an issue of precise production of machine parts evaluation and analysis. It works with data that came from serial production in automotive industry, where high precision and small amount of rejected parts play a big role. In our case, in spite of high precision of production, is there still significant number of rejections. From this reason, we did a detailed analysis of provided data form measurement in production line for giving suggestions, which should lead to production process improvement. For the detailed analysis authors choose the Pareto analysis, which belongs to the seven basic tools of quality management system. The requirements for constant improvement of the process came from TS 16949 standard that works with quality management system in automotive industry. [4, 5]

Evolution of market expectations leads to new solutions in quality control. Nowadays, in most cases control of geometry in industry is carried out using devices that apply coordinate measuring technique [8].

\section{Problem description}

Our input was a series of measurement data that came from $100 \%$ part control from a serial production of a part for automotive industry (Fig.1b). All parts at the end of production process were measured by optical comparator KEYENCE IM series. [6] Identified rejected parts are eliminated. In accordance to technical specification, 15 
dimensions are measured and evaluated for each part. An example of one position of the part during its evaluation is in (Fig.1a).

The Pareto analysis of tolerance outlier dimensions occurrence frequency was done. Pareto analysis belongs to the seven basic tool of quality control. The main idea of Pareto analysis is that most of effect (80\%) comes from minimum cause $(20 \%)$. The main aim is to graphically display this asymmetrical distribution. The diagram shows causes of a problem, which are divided in accordance to their importance and are expressed, in most cases, by their cumulative frequency.
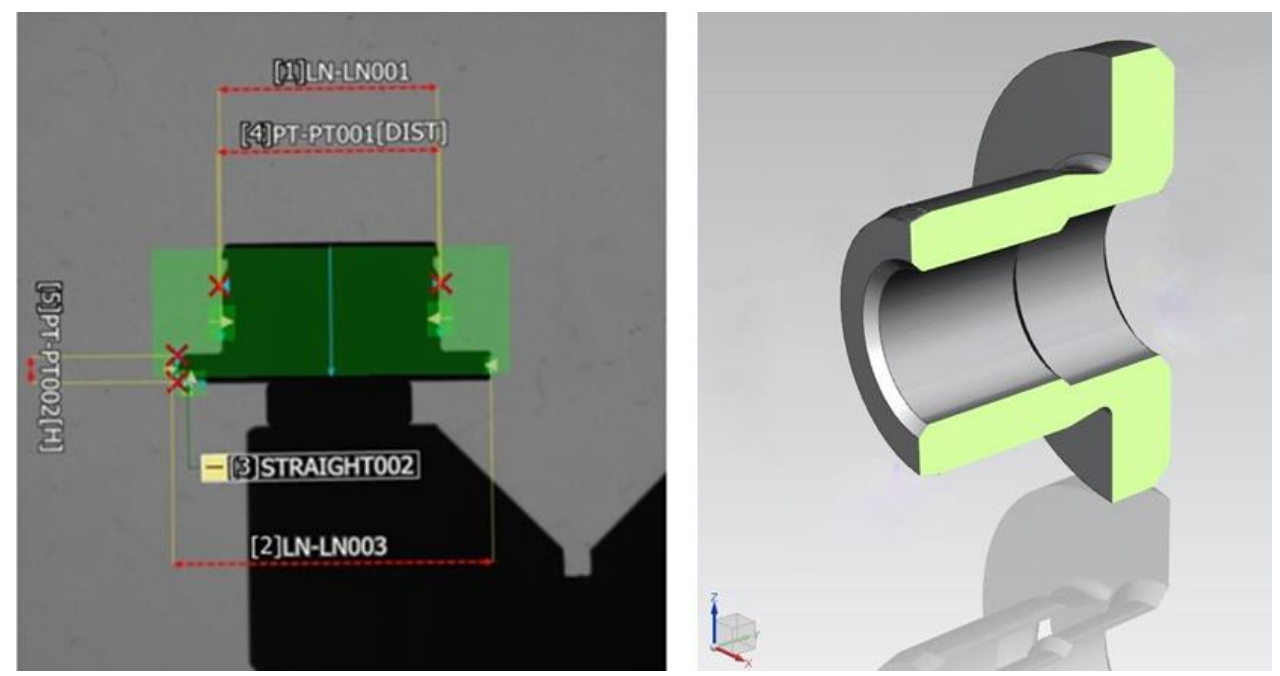

Fig. 1. Manufactured part during optical evaluation (a) and 3-D model of it (b)

In our case are measured dimensions chosen instead of errors and we are expressing cumulative frequency of dimensions out of tolerance. The data was sorted downwards from maximal count of dimensions that lie out of tolerance to the minimal. Then the data was depicted in the histogram. After that, cumulative frequencies were highlighted and Lorentz cumulative curve was created. We can draw a vertical line from the intersection of $80 \%$ horizontal line and Lorentz cumulative curve. This vertical line divides our histogram into two parts. The first part shows crucial minority of errors or, in our case, dimensions, which represent the majority of errors or rejected parts occurrence [1].

From this analysis we can say which of the controlled dimension makes the biggest "problems", so it is often out of the tolerance limits. Now we have dimensions that we must take a closer look to.

Controlled dimensions from our case are showed in Table 1 and they are sorted in accordance to number of outliers. The Table 1 also contains relative frequency and cumulative frequency.

\begin{tabular}{|c|c|c|c|}
\hline $\begin{array}{c}\text { Controlled } \\
\text { dimension }\end{array}$ & $\begin{array}{c}\text { Frequency of } \\
\text { outliers }\end{array}$ & $\begin{array}{c}\text { Relative frequency } \\
\text { of outliers }\end{array}$ & $\begin{array}{c}\text { Cumulative } \\
\text { frequency of outliers }\end{array}$ \\
\hline 8 & 80 & $47 \%$ & $47 \%$ \\
\hline 9 & 43 & $25 \%$ & $72 \%$ \\
\hline 7 & 18 & $11 \%$ & $82 \%$ \\
\hline 11 & 10 & $6 \%$ & $88 \%$ \\
\hline 6 & 8 & $5 \%$ & $93 \%$ \\
\hline 4 & 7 & $4 \%$ & $97 \%$ \\
\hline 14 & 3 & $2 \%$ & $99 \%$ \\
\hline 5 & 2 & $1 \%$ & $100 \%$ \\
\hline 1 & 0 & $0 \%$ & $100 \%$ \\
\hline 2 & 0 & $0 \%$ & $100 \%$ \\
\hline 3 & 0 & $0 \%$ & $100 \%$ \\
\hline 10 & 0 & $0 \%$ & $100 \%$ \\
\hline 12 & 0 & $0 \%$ & $100 \%$ \\
\hline 13 & 0 & $0 \%$ & $100 \%$ \\
\hline 15 & 0 & $0 \%$ & $100 \%$ \\
\hline
\end{tabular}

Table 1. Frequency of outliers 


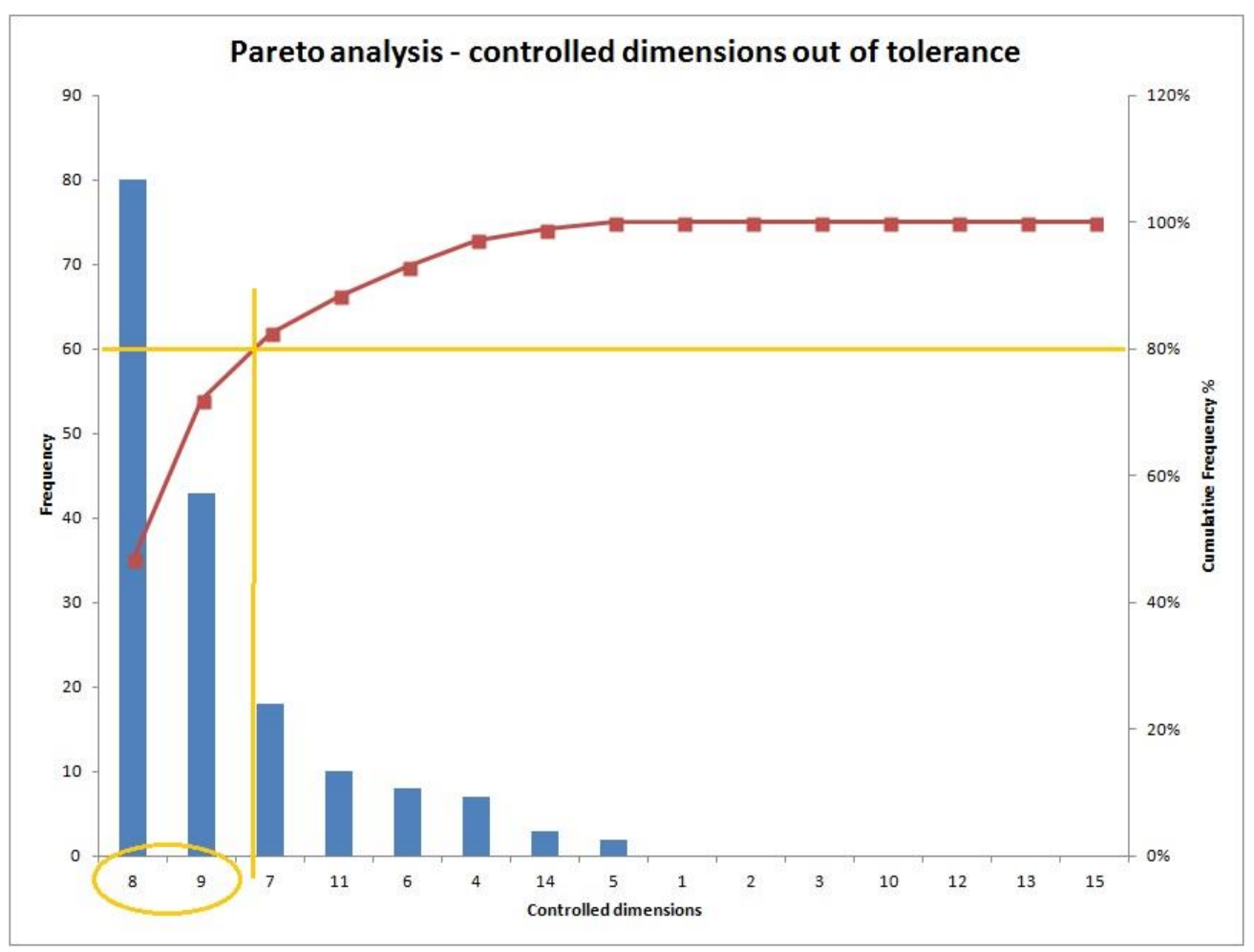

Fig. 2. Pareto chart

From previous analysis we can say which dimensions cause the most of problems. That means they are often out of tolerance. In our case, we can see in the Figure 2 that we must have a closer look at dimensions number 8 and 9. If we eliminate the errors occurrence in those dimensions production, we can also eliminate the most of rejected parts. In both cases, the dimensions represent roundness of the center hole.

\section{Analysis evaluation}

We took a one batch from the production to measure them using our high precision laboratory equipment. The aim of this new measurement is to prove our idea about using the Pareto analysis for data from serial production analysis and for verification of results the optical measurement system, which should be not sufficient for evaluation of roundness measured at such part as we have. Because the optical measurement system works only with 2-D image that is, in case of the inner hole, build from a projection of the whole cylinder. However, in many cases it is necessary to measure an element with a incomplete contour.[7] International standard [2] says that the produced hole must fulfill the described tolerance in any cross-section that is perpendicular to the axis of analyzed hole.

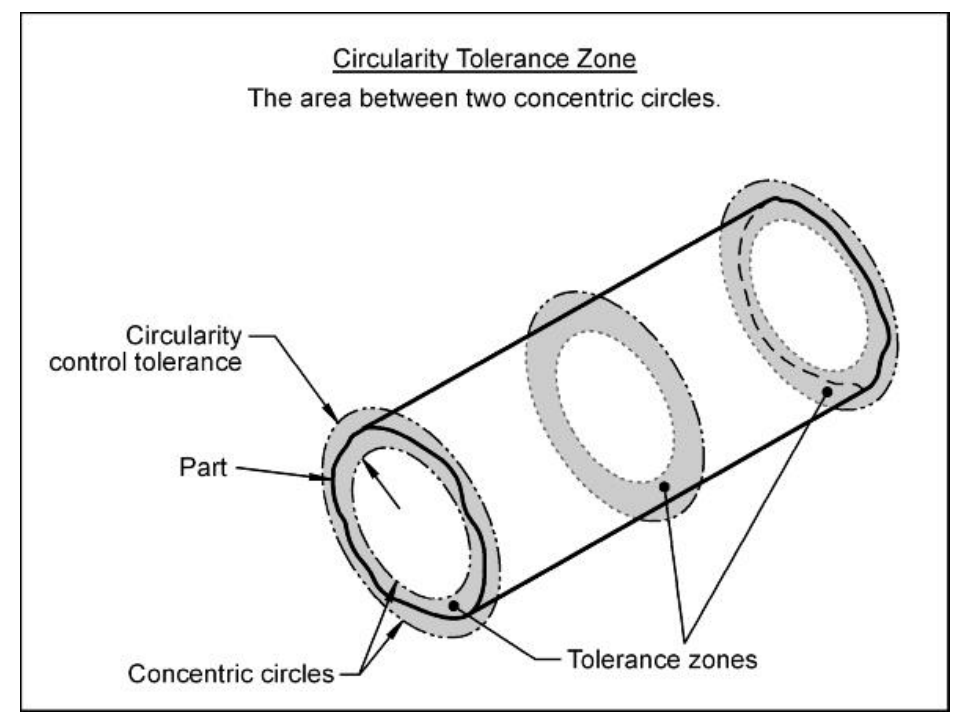

Fig. 3. Usual measurement scheme for roundness (the beginning, the end and the middle of the part) [3] 
Usually, the roundness is measured at the beginning, at the end and in the middle of the part (Figure 3). For better image about the produced hole, authors decided to take 5 measurements upon height of the part. The measurement of roundness was carried out using Taylor Hobbson Talyrond 585 high precise laboratory roundness instrument. The rest of dimensions were measured by ZEISS Prismo Navigator 7 CMM. Both measurement instruments work under laboratory conditions and produce very precise results of measurement. The uncertainty of measurement is $0.1 \mu \mathrm{m}$ in case of roundness instrument and $0.9 \mu \mathrm{m}$ in case of CMM.

The example of measured data taken from roundness instrument is shown in Table 2.

\begin{tabular}{|c|c|c|c|c|c|}
\hline \multicolumn{7}{|c|}{ Roundness in cross-section - dimension no. 8 } \\
\hline Nr. part & A & B & C & D & E \\
\hline 1 & 1.80 & 1.75 & 1.35 & 1.09 & $\mathbf{2 . 3 2}$ \\
\hline 2 & 1.16 & 0.96 & 0.68 & 0.84 & 1.02 \\
\hline 3 & 1.65 & 0.94 & 0.63 & 1.04 & 1.78 \\
\hline 4 & 1.47 & 1.06 & 0.77 & 0.75 & 1.44 \\
\hline 5 & 1.42 & 1.02 & 1.10 & 0.80 & 1.91 \\
\hline 6 & 1.13 & 1.07 & $\mathbf{2 . 9 6}$ & 1.45 & 1.78 \\
\hline
\end{tabular}

Table 2. An example of measured data

\section{Conclusion}

An example of measured data (dimension no. 8) is shown in Table 2. We can see that in case of part number 6, the roundness value in the middle cross-section is out of tolerance. That can prove that evaluating the roundness only with optical measurement system is not enough.

From the database we picked up only the maximal values and we repeated the calculation that gives a base for Pareto analysis on our new data and it is showed in Table 3.

\begin{tabular}{|c|c|c|c|}
\hline $\begin{array}{c}\text { Controlled } \\
\text { dimension }\end{array}$ & $\begin{array}{c}\text { Frequency of } \\
\text { outliers }\end{array}$ & $\begin{array}{c}\text { Relative frequency } \\
\text { of outliers }\end{array}$ & $\begin{array}{c}\text { Cumulative } \\
\text { frequency of outliers }\end{array}$ \\
\hline 8 & 84 & $47 \%$ & $47 \%$ \\
\hline 9 & 45 & $25 \%$ & $73 \%$ \\
\hline 7 & 18 & $10 \%$ & $83 \%$ \\
\hline 11 & 10 & $6 \%$ & $89 \%$ \\
\hline 6 & 8 & $5 \%$ & $93 \%$ \\
\hline 4 & 7 & $4 \%$ & $97 \%$ \\
\hline 14 & 3 & $2 \%$ & $99 \%$ \\
\hline 5 & 2 & $1 \%$ & $100 \%$ \\
\hline 1 & 0 & $0 \%$ & $100 \%$ \\
\hline 2 & 0 & $0 \%$ & $100 \%$ \\
\hline 3 & 0 & $0 \%$ & $100 \%$ \\
\hline 10 & 0 & $0 \%$ & $100 \%$ \\
\hline 12 & 0 & $0 \%$ & $100 \%$ \\
\hline 13 & 0 & $0 \%$ & $100 \%$ \\
\hline 15 & 0 & $0 \%$ & $100 \%$ \\
\hline
\end{tabular}

Table 3. Frequency of outliers - new measurement

From the new measurement, which was carried out with contact method, we can see that the number of faulty parts is slightly higher (84 instead of 80 at number 8 and 45 instead of 40 at number 9), than the optical measurement method can reveal. It means in this case, we prove that the optical measurement method is not able to catch all faulty parts (for example conical hole) that could be rejected and such parts could cause the parts reclamation from the customer side. The other dimensions did not show differences. 
Because of high requirements for precise production and production process stability in automotive industry, we have for the company two main suggestions:

- Have a look at the manufacturing technology of the holes. Nowadays the production is done by drilling and then internal turning. We suggest to test other strategies of manufacturing:

1) Keep the same technology with change of cutting conditions or tool's geometry.

2) Use new strategy. Drilling and reaming.

- Further statistic evaluation of the production process with evaluation of stability and capability of the process.

Authors used a Pareto analysis for evaluation of measured data. Pareto analysis is usually used for analysis of rejected products and analysis of rejections. From the article we can see that the Pareto analysis could be also used for evaluation of measured data in mass production.

\section{Acknowledgments}

This paper includes results created within the project SGS-2016-005.

\section{References}

[1] Andersen, B., Fagerhaug, T.: Analysis of the root causes - Simplified tools and methods, ČSJ, Praha, 2011, ISBN: 978-80-02-02356-2

[2] ISO 1101:2012, pages 40-41

[3] Roundness evaluation, figure available on line http://www.engineeringessentials.com/gdt/circularity/circularity.htm, date cited: 08-09-2016

[4] Liviu Dorin Pop, Nagy Elod: Improving Product Quality by Implementing ISO / TS 16949, Procedia Technology, Volume 19, 2015, Pages 1004-1011

[5] ČSN ISO/TS 16949:2009, Quality management system for automotive industry

[6] Martin Melichar, Dana Kubátová: Processing Data from Automatic Measurement Device, Procedia Engineering, Volume 100, 2015, Pages 899-906

[7] Bartosz Gapinski, Michal Wieczorowski: Measurement of Diameter and Roundness on Incomplete Outline of Element with Three-lobbing Deviation, Procedia Engineering, Volume 69, 2014, Pages 247-254

[8] Bartosz Gapinski, Michał Wieczorowski, Lidia Marciniak-Podsadna, Bogdan Dybala, Grzegorz Ziolkowski: Comparison of Different Method of Measurement Geometry Using CMM, Optical Scanner and Computed Tomography 3D, Procedia Engineering, Volume 69, 2014, Pages 255-262 